\title{
ANALISIS SERVICE LIFE TERHADAP BERBAGAI JENIS MATERIAL REKLAMASI DIATAS TANAH LUNAK
}

\author{
Jessica Immanuel $^{1}$ dan Chaidir Anwar Makarim ${ }^{2}$ \\ ${ }^{1}$ Program Studi Sarjana Teknik Sipil, Universitas Tarumanagara, Jl. Letjen S. Parman No.1 Jakarta \\ Email: jessicaimmanuel@yahoo.com \\ ${ }^{2}$ Program Studi Sarjana Teknik Sipil, Universitas Tarumanagara, Jl. Letjen S. Parman No.1 Jakarta \\ Email: chaidir259@gmail.com
}

\begin{abstract}
ABSTRAK
Perkembangan teknologi yang pesat di masa kini dalam setiap aspek kehidupan berbanding lurus dengan meningkatnya aktivitas yang dilakukan oleh manusia Hal ini mendorong meningkatnya kebutuhan manusia akan lahan, sedangkan lahan yang tersedia konstan. Problematika ini memunculkan suatu solusi yang disebut reklamasi. Reklamasi adalah kegiatan yang dilakukan dengan tujuan menambah luasan daratan untuk suatu aktivitas yang sesuai di wilayah tersebut. Dalam suatu proyek pembuatan lahan reklamasi, pada umumnya digunakan material pasir. Namun seiring berkembangnya jaman, digunakan material lain yang dianggap lebih murah dan jumlahnya banyak. Pasir, batu, dan lumpur adalah beberapa jenis tanah yang seringkali digunakan sebagai material pengisi lahan reklamasi. Penggunaan suatu jenis material reklamasi bergantung pada beberapa pertimbangan, beberapa yang perlu diperhatikan adalah sifat dan dampak penurunan yang akan terjadi di masa depan. Sedangkan, setiap struktur atau bangunan yang akan berdiri diatasnya direncanakan memiliki umur layannya masing-masing. Dampak penurunan pada setiap jenis material reklamasi yang berbeda-beda dapat berdampak pada suatu umur layan suatu bangunan yang akan berdiri diatasnya. Dari beberapa data tanah yang mewakili sifat suatu jenis material, akan dilakukan analisis penurunan (konsolidasi) dengan suatu program pembantu. Dari hasil analisis, dapat diinterpretasikan perbedaan penurunan yang terjadi dan dampak yang dapat ditimbulkan terhadap rencana umur layan suatu bangunan tertentu. Analisis umur layan terhadap jenis tanah material reklamasi tertentu diperlukan guna mencapai suatu umur layan yang direncanakan.
\end{abstract}

Kata kunci: material reklamasi, konsolidasi, rangkak, umur layan

\section{PENDAHULUAN}

\section{Latar belakang}

Perkembangan teknologi yang pesat dalam setiap aspek kehidupan manusia sudah tak terelakkan lagi. Manusia terus menerus mengembangkan segala sesuatu mulai dari hal yang sederhana hingga hal yang melewati batas pemikiran orang pada umumnya. Kebutuhan akan lahan pun muncul dimana lahan merupakan kebutuhan utama dalam pelaksanaan pembangunan. Lambat laun, hal ini menimbulkan problematika baru ketika permintaan akan lahan tidak seimbang dengan lahan yang tersedia. Tak lama kemudian, muncullah solusi yang disebut sebagai reklamasi.

Salah satu aspek yang penting dan perlu dipertimbangkan dalam proyek reklamasi adalah service life (umur layan) setiap struktur yang akan berdiri diatasnya. Setiap struktur yang hendak dibangun direncanakan memiliki umur layannya masing-masing menurut tujuannya. Banyak hal yang harus diperhatikan agar suatu umur layan yang direncanakan pada suatu struktur tercapai.

Salah satunya adalah pemilihan jenis tanah material reklamasi. Hal ini penting dipertimbangkan dampaknya terhadap berbagai faktor service life suatu struktur. Jenis material yang berbeda akan menyebabkan penurunan (konsolidasi) yang berbeda pula. Melalui skripsi ini, akan dilakukan analisis hubungan pemilihan jenis tanah material reklamasi terhadap berbagai faktor yang mempengaruhi service life suatu struktur.

\section{Tujuan penelitian}

Tujuan dari penelitian ini adalah mengetahui kelebihan dan kekurangan dari berbagai jenis material reklamasi yang digunakan, mengetahui penuunan yang terjadi pada suatu lahan reklamasi menggunakan suatu program pembantu, dan mengetahui hubungan dan pengaruh pemilihan jenis tanah material reklamasi menggunakan suatu program pembantu. 


\section{Pengertian reklamasi}

Reklamasi berasal dari kosa kata dalam bahasa Inggris, yaitu to reclaim yang berarti memperbaiki sesuatu yang rusak. Reklamasi juga dapat diartikan sebagai proses menciptakan lahan baru dari laut, dasar sungai, ataupun dasar danau.

\section{Manfaat dan tujuan reklamasi}

Tujuan reklamasi yaitu untuk menjadikan kawasan berair yang rusak atau belum termanfaatkan menjadi suatu kawasan baru yang lebih baik dan bermanfaat.

\section{Sumber material reklamasi}

Dalam realisasi pelaksanaan penimbunan reklamasi, biasanya persyaratan teknis tersebut disederhanakan atau dibuat praktis, menjadi:

1. Berupa tanah pasir bercampur kerikil dan sedikit lanau

2. Harus bersih dan bebas dari bahan organis dan kotoran

3. Diameter butiran maksimum $=20 \mathrm{~mm}$

4. Persentasi material berdiameter halus yaitu yang lebih kecil dari $0.08 \mathrm{~mm}$ adalah lebih kecil dari $20 \%$

5. Relative density (Dr) timbunan minimum $=80 \%$ untuk zone diatas muka air pasang, dan minimum $=60 \%$ pada zona dibawah muka air pasang.

6. Koefisien permeabilitas (k) minimum $=1 \times 10^{-5} \mathrm{~m} / \mathrm{s}$

Pada umumnya, material timbunan yang baik adalah material pasir yang heterogen (well graded sands). Namun seiring berjalannya waktu dan berkembangnya teknologi, beberapa material seperti batu dan lumpur pun digunakan. Material tersebut digunakan karena beberapa faktor, yaitu biaya, transportasi, dan lain-lain.

\section{Penurunan (konsolidasi)}

Jika suatu lapisan tanah dibebani, maka tanah akan mengalami regangan atau penurunan (settlement), atau boleh dikatakan tanah yang mengalami tegangan akan mengalami regangan dalam tanah tersebut. Pada tanah berbutir halus yang berada dibawah muka air tanah terjadi penurunan konsolidasi (consolidation settlement). Penurunan yang terjadi memerlukan waktu yang lama. Penurunan tanah merupakan peristiwa termampatnya suatu lapisan tanah, dapat dikarenakan karena beban luar atau pemompaan air. Jenis penurunan ada beberapa:

- Penurunan segera (immediate settlement): penurunan akibat deformasi elastis tanah kering, basah, dan jenuh air tanpa adanya perubahan kadar air.

- Penurunan konsolidasi primer (primary settlement): penurunan yang terjadi akibat terdisipasinya tegangan air pori berlebih seiring dengan berjalannya waktu.

- Penurunan konsolidasi sekunder (secondary settlement): penurunan yang terjadi setelah penurunan konsolidasi primer.

\section{Penurunan sekunder (secondary consolidation)}

Penurunan ini terjadi umumnya setelah penurunan primer terjadi, didefinisikan sebagai penyesuaian kerangka tanah sesudah tekanan pori yang berlebih menghilang. Penurunan sekunder tergantung pada waktu dan dapat berlangsung dalam waktu yang lama. Penurunan yang diakibatkan oleh konsolidasi sekunder sangat penting untuk semua jenis tanah organik dan tanah anorganik yang sangat mampu mampat (compressible). Untuk lempung anorganik yang terlalu terkonsolidasi, indeks pemampatan sekunder adalah sangat kecil sehingga dapat diabaikan.

\section{Service life (umur layan)}

Menurut W.P.S.Dias (2003) dalam tulisannya yang berjudul Factors Influencing the Service Life of Buildings, ditulis bahwa umur layan struktur bergantung pada 5 buah faktor, seperti:

- Tujuan bangunan (their purpose)

- Pertimbangan atas aspek sosial - ekonomi (socio - economic consideration)

- Material konstruksi (material of construction)

- Lingkungan di sekitar (surrounding environment)

- Derajat pemeliharaan (degree of maintenance) 


\section{METODOLOGI PENELITIAN}

\section{Metode pengumpulan data}

Metode yang digunakan untuk pengumpulan data penelitian ini adalah teknik dokumentasi yaitu pengumpulan data dari proyek. Setelah data berhasil didapatkan, kemudian dilakukan beberapa korelasi parameter tanah sehingga diperoleh parameter yang dibutuhkan untuk melakukan analisis perbedaan penurunan (konsolidasi) oleh setiap jenis material dan dampak yang ditimbulkan pada umur layan suatu bangunan.

\section{Metode analisis data}

Metode analisis yang digunakan untuk menganalisa data menggunakan suatu program pembantu. Sebelum dilakukannya analisis data, perlu adanya studi literature dengan mencari dasar - dasar teori dan sumber data seperti journal, buku referensi untuk mendapatkan rumus - rumus.

\section{ANALISIS DAN PEMBAHASAN}

\section{Kesimpulan parameter}

Berdasarkan hasil uji lapangan, dan hasil korelasi, dapat dianalisis untuk mendapatkan berbagai macam parameter yang akan digunakan untuk melakukan pemodelan pada program. Berikut merupakan kesimpulan parameter yang digunakan untuk pemodelan konsolidasi lapisan tanah pada suatu program pembantu yang dapat dilihat pada tabel 1 dan tabel 2 sebagai berikut.

Tabel 1. Parameter tanah suatu proyek reklamasi di Jakarta (Suatu Proyek Reklamasi di Jakarta)

\begin{tabular}{lcc}
\hline \multicolumn{1}{c}{ Parameter } & $\begin{array}{c}\text { Holocene } \\
\text { Clay }\end{array}$ & Dredged Mud \\
\hline$\gamma-$ Unit Weight $\left(\mathrm{kN} / \mathrm{m}^{2}\right)$ & 14.3 & 12 \\
\hline$\gamma_{\mathrm{sat}}-$ Sat. Unit Weight $\left(\mathrm{kN} / \mathrm{m}^{2}\right)$ & 16.3 & 14 \\
\hline$v-$ Poisson Ratio & 0.2 & 0.15 \\
\hline $\mathrm{Cc}-$ Compression Index & 0.96 & 1.08 \\
\hline $\mathrm{Cr}-$ Recompression Index & 0.146 & 0.18 \\
\hline $\mathrm{Cv}-$ Coefficient of Consolidation & 1.33 & 3.5 \\
$\left(\mathrm{~m}^{2} /\right.$ year $)$ & & 0.036 \\
\hline $\mathrm{C} \alpha-$ Secondary Consolidation & 0.036 & 3.5 \\
Coefficient & & 1 \\
\hline $\mathrm{e}_{\mathrm{o}}-$ Initial Void Ratio & 3 & \\
\hline OCR - Over-Consolidation Ratio & & \\
\hline
\end{tabular}

Tabel 2. Parameter untuk jenis material batu dan pasir

\begin{tabular}{lcc}
\hline \multicolumn{1}{c}{ Parameter } & Rock/Gravel & Dense Sand \\
\hline$\gamma-$ Unit Weight $\left(\mathrm{kN} / \mathrm{m}^{2}\right)$ & 17 & 16 \\
\hline$\gamma_{\mathrm{sat}}-$ Sat. Unit Weight $\left(\mathrm{kN} / \mathrm{m}^{2}\right)$ & 22 & 20 \\
\hline$v-$ Poisson Ratio & 0.2 & 0.3 \\
\hline $\mathrm{Cc}-$ Compression Index & 0.0001 & 0.01 \\
\hline $\mathrm{Cr}-$ Recompression Index & 0.00002 & 0.002 \\
\hline $\mathrm{k}-$ Permeability $\left(\mathrm{cm}^{2} / \mathrm{s}\right)$ & 1 & 100 \\
\hline $\mathrm{C} \alpha-\quad$ Secondary Consolidation & - & - \\
Coefficient & & 0.5 \\
\hline $\mathrm{e}_{\mathrm{o}}-$ Initial Void Ratio & 0.36 & \\
\hline
\end{tabular}




\begin{tabular}{lll}
\hline OCR - Over-Consolidation Ratio & 1 & 1
\end{tabular}

\section{Analisis penurunan dengan material pasir (dense sand)}

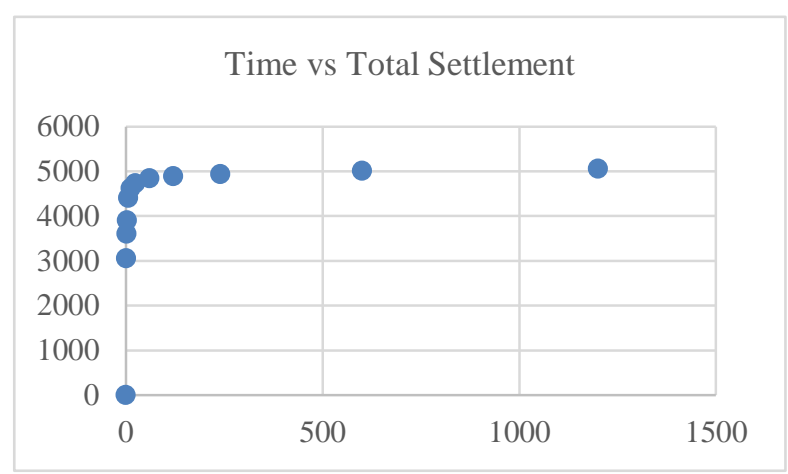

Gambar 1. Grafik Total Settlement Material Pasir

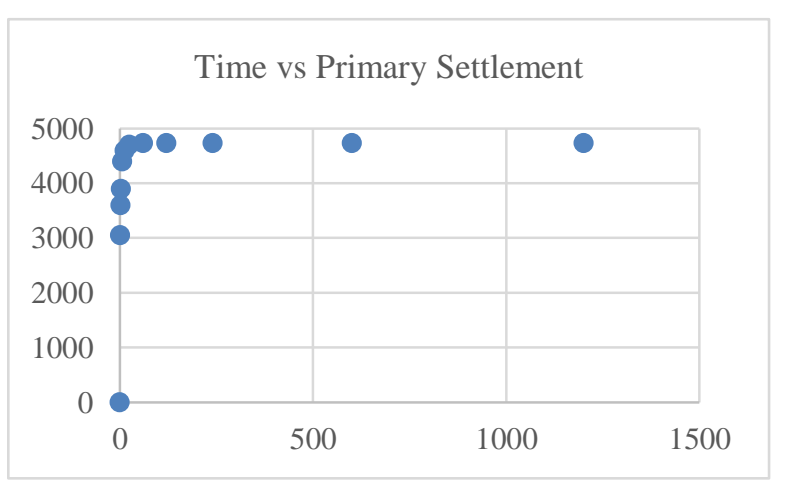

Gambar 2. Grafik Primary Settlement Material Pasir

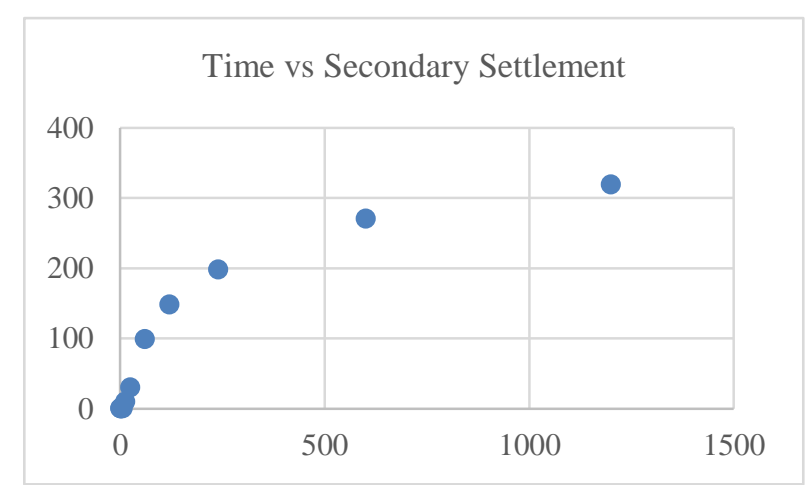

Gambar 3. Grafik Secondary Settlement Material Pasir

Dari hasil output program untuk lapisan tanah dengan material pasir, didapatkan hasil maksimum (hingga 100 tahun) penurunan total (total settlement) sebesar 5.0531 meter (Gambar 1), penurunan primer (primary settlement) sebesar 4.734 meter (Gambar 2), dan penurunan sekunder (secondary settlement) sebesar 0.3189 meter (Gambar 3). Dari grafik tersebut, dapat terlihat penurunan sekunder yang terjadi dari waktu ke waktu cenderung kecil dan tidak signifikan.

Besaran penurunan yang terjadi dianggap baik dan kecil, mengingat material reklamasi terbaik hingga saat ini adalah material pasir. Pada pemodelan lapisan tanah reklamasi ini, yang mengalami penurunan sekunder hanya lapisan tanah asli dibawahnya (holocene clay). Hal ini merupakan nilai tambah untuk material pasir karena tidak 
memiliki andil dalam penurunan jangka panjang (secondary settlement), dampaknya dianggap kecil sekali sehingga dapat diabaikan. Nilai permeabilitas yang tinggi pada material pasir dianggap menunjukkan drainase material ini baik (Budhu, 2011), sehingga pemadatan tanah dan konsolidasi dapat terjadi dengan cepat. Selain itu, material pasir yang tidak terlalu berat, transportasi material ke lokasi reklamasi pun menjadi lebih mudah. Salah satu hal yang menjadi masalah utama dari pemilihan jenis material ini adalah fenomena liquifaksi yang kerap terjadi pada material ini.

Salah satu studi kasus proyek reklamasi yang menggunakan pasir adalah proyek reklamasi Changi East, Singapura. Proyek Changi East dilakukan dari tahun 1991 hingga 2005 di lepas pantai untuk memperluas Bandara Internasional Changi dan perkembangan infrastruktur lain di Singapura (Arulrajah, 2008). Berdasarkan hasil yang didapat, dapat ditarik kesimpulan lapisan reklamasi dengan material pasir dikatakan memiliki daya dukung yang cukup kuat dan dianggap baik sebagai jenis material reklamasi.

\section{Analisis penurunan dengan material lumpur (dredged mud)}

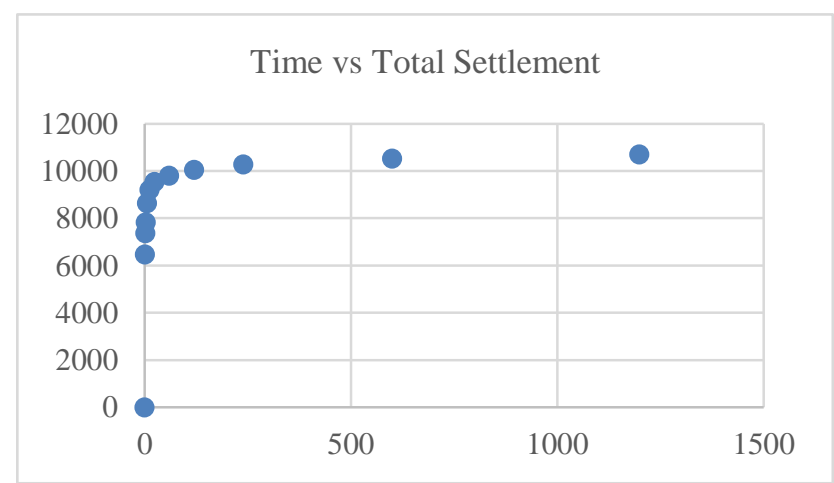

Gambar 4. Grafik Total Settlement Material Lumpur

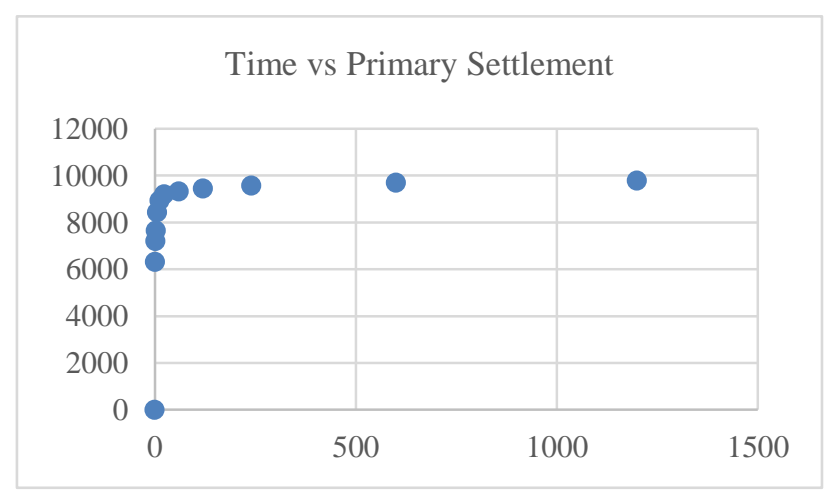

Gambar 5. Grafik Primary Settlement Material Lumpur

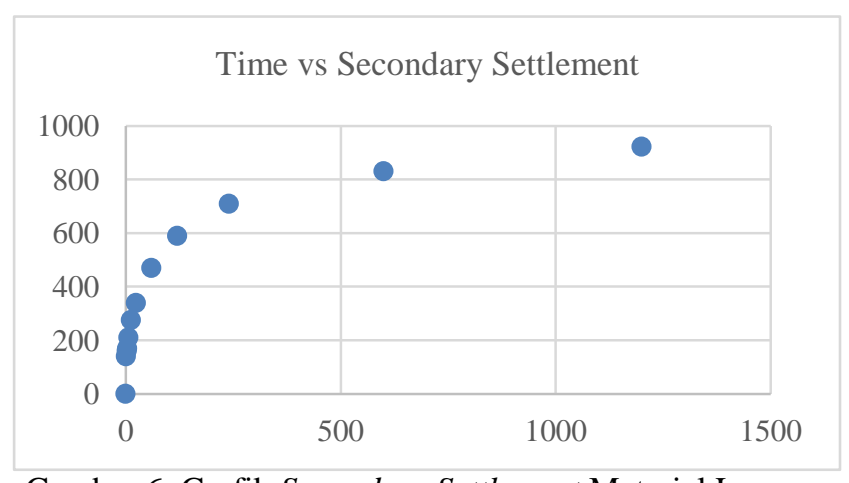

Gambar 6. Grafik Secondary Settlement Material Lumpur

Dari hasil output program, untuk lapisan tanah reklamasi dengan material lumpur didapatkan hasil maksimum penurunan total (total settlement) sebesar 9.7789 meter (Gambar 4), penurunan primer (primary settlement) sebesar 8.8562 meter (Gambar 5), dan penurunan sekunder (secondary settlement) sebesar 0.9227 meter (Gambar 6). Dari grafik tersebut, terlihat penurunannya jauh lebih besar dan signifikan dibanding dengan lapisan tanah dengan material sebelumnya. Hal ini disebabkan material lumpur ini turut menimbulkan secondary consolidation. 
Harganya yang murah dan jumlahnya yang banyak, mendorong beberapa proyek reklamasi yang menggunakan lumpur sebagai material pengisi reklamasi. Yang menjadi masalah besar dalam pemakaian jenis material ini, adalah tingkat permeabilitasnya yang sangat rendah. Tingkat permeabilitas yang rendah menyebabkan material ini memiliki tingkat drainase yang sangat buruk. Drainase yang buruk ini membuat kandungan air yang terperangkap diantara pori sulit untuk keluar, yang menyebabkan konsolidasi untuk jangka waktu yang sangat lama. Penggunaan material ini perlu diberi perhatian lebih pada secondary settlement yang ditimbulkan.

Kasus secondary settlement pada reklamasi yang dapat diambil adalah kasus Bandar Udara Internasional Kansai, Jepang. Konsolidasi yang terjadi sangat besar jauh melewati perhitungan awal konsolidasi. Hal ini disebabkan pada tanah aslinya (clay) memiliki kandungan air yang besar dan mengejutkan. Diperkirakan terdapat $70 \%$ kandungan air yang terperangkap di antara pori tersebut. Selain itu, material pengisi reklamasi yang berupa lumpur juga turut memberi sumbangan penurunan rangkak yang cukup besar. Berat dari material pengisi dan preloading menekan air untuk keluar dari pori tanah lempung tersebut, dan menyebabkan konsolidasi terjadi. Lapisan tanah lempung dapat menjadi keras setelah air ditekan keluar, dan penurunan akan berhenti setelah tanah lempung ini seluruhnya menjadi keras dan dapat menahan beban dari pulau diatasnya. Namun, hingga saat ini penurunan masih tetap terjadi dan belum berhenti. (KIX, 2016). Dapat disimpulkan bahwa jenis material lumpur ini dapat dikatakan kurang baik sebagai material reklamasi. Namun, beberapa faktor seperti biaya dan kemudahan material ini didapatkan mendorong proyek reklamasi untuk menggunakannya. Diperlukan perhatian khusus pada secondary settlement yang ditimbulkan, baik pada lapisan tanah pengisi maupun lapisan tanah asli.

\section{Analisis penurunan dengan material batu (rock/gravel)}

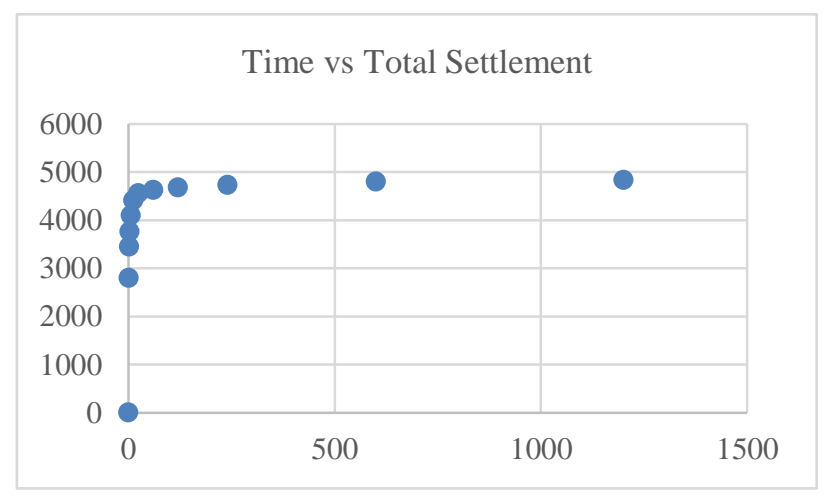

Gambar 7. Grafik Total Settlement Material Batu

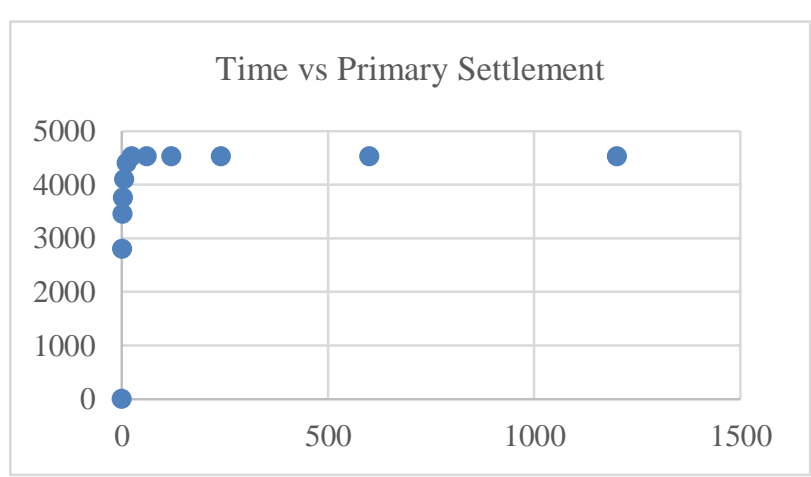

Gambar 8. Grafik Primary Settlement Material Batu 


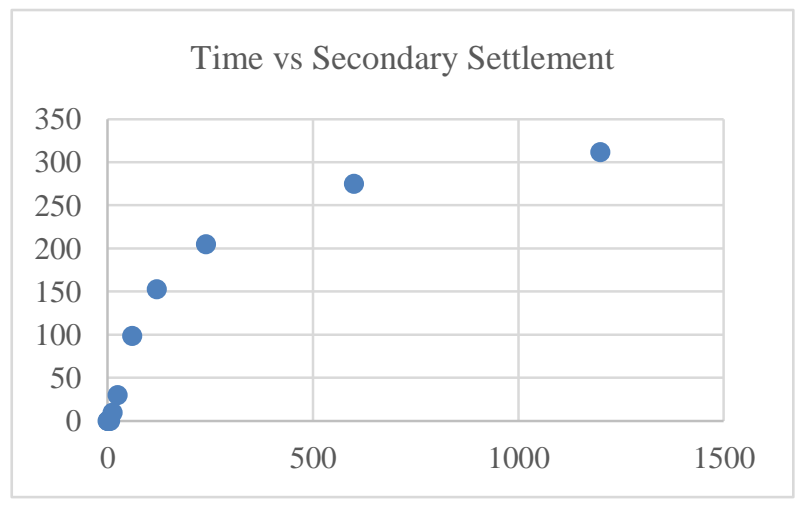

Gambar 9. Grafik Secondary Settlement Material Batu

Dari hasil output program, untuk lapisan tanah reklamasi dengan material batu didapatkan hasil maksimum penurunan total (total settlement) sebesar 4.8355 meter (Gambar 7), penurunan primer (primary settlement) sebesar 4.5228 meter (Gambar 8), dan penurunan sekunder (secondary settlement) sebesar 0.3127 meter (Gambar 9). Dari grafik tersebut, dapat terlihat penurunan (konsolidasi) yang terjadi kurang lebih sama dengan material pasir.

Material batu memiliki berat yang lebih besar dari material pasir, yang membuat material ini lebih sulit dipindahkan ke lokasi reklamasi. Ukuran yang besar pada material ini membuat material batu tidak bisa dipadatkan dengan mudah, dan dapat merusak alat pengerukan reklamasi (HKDSE, 2014). Apabila ukurannya terlalu besar, maka material ini perlu dipecahkan ke ukuran yang lebih kecil untuk mempermudah pemadatan. Cuaca juga dapat memberikan dampak yang buruk untuk material ini. Dampak yang ditimbulkan berupa pelapukan yang dapat menyebabkan batuan hancur menjadi bagian yang lebih kecil, sehingga dapat menyebabkan penurunan signifikan pada void ratio dan terjadinya konsolidasi di masa yang akan datang. (Pratikso, 2008). Diperlukan perhatian dalam pemilihan jenis batu yang digunakan, batuan yang baik digunakan adalah batuan beku yang memiliki ketahanan yang tinggi terhadap proses erosi dan pelapukan.

Salah satu studi kasus proyek reklamasi yang menggunakan batuan sebagai material reklamasi adalah proyek reklamasi di Lamma Island, Hong Kong. Sebagian besar proyek reklamasi di Hong Kong berskala besar menggunakan batu sebagai material pengisi reklamasi, karena membutuhkan jumlah yang sangat besar. Namun, beberapa masalah timbul dari penggunaan material batu ini, diantaranya biaya yang cukup mahal dalam pengurugan, dan potensi longsor pada sumber tanah urugan. Selain itu, batu dapat mengalami erosi yang disebabkan oleh hujan, kelembaban, dan panas yang disebabkan oleh faktor cuaca. Disamping beberapa kekurangannya, material batu ini dapat dikatakan cukup baik sebagai material reklamasi. Salah satu kelebihannya adalah material ini tidak menimbulkan secondary settlement, dianggap tidak ada karena sangat kecil. Selain itu, material ini memiliki jumlah yang besar dan sangat cocok untuk proyek reklamasi berskala besar.

\section{Tujuan bangunan}

Setiap struktur dengan tujuannya masing-masing memiliki service life (umur layan) yang berbeda-beda pula (W.P.S. Dias, 2003). Menurut British Standart 7543:1992, menetapkan umur layan normal suatu struktur adalah 60 tahun. Sedangkan menurut British Standart EN 1992-1-1:2008, menetapkan umur layan normal suatu struktur lebih rendah, yaitu 50 tahun. Peninjauan akan dilakukan pada bangunan dermaga dan bangunan perkantoran. Berdasarkan tujuannya, dermaga dianggap bangunan publik, direncanakan mencapai umur layan 100 tahun. Sedangkan bangunan perkantoran termasuk bangunan pribadi, direncanakan mencapai umur layan 60 tahun.

\section{Pertimbangan aspek sosial ekonomi}

Perkembangan teknologi, aspek sosial dan ekonomi yang terus menerus berdampak pada aktivitas yang terjadi pada suatu jenis bangunan. Umur layan suatu bangunan harus dapat mempertimbangkan perkembangan yang akan terjadi di masa yang akan datang, baik dalam aspek sosial, ekonomi, maupun budaya. Aktivitas yang terus berkembang ini dapat berdampak pada peningkatan maupun penurunan beban yang dipikul oleh suatu jenis tanah.

Perkembangan arus ekonomi dapat mengalami kenaikan dan penurunan di masa depan. Kenaikan arus ekonomi yang pesat dapat meningkatkan kegiatan ekonomi luar negeri, yaitu kegiatan ekspor dan impor. Suatu dermaga peti kemas yang awalnya hanya menampung $10.000 \mathrm{ton} / \mathrm{m}^{3}, 1$ tahun kemudian terjadi peningkatan ekonomi hingga 50.000 ton $/ \mathrm{m}^{3}$. Peningkatan beban bongkar muat pada dermaga ini akan berdampak peningkatan 
penurunan/konsolidasi yang terjadi. Jenis material reklamasi harus dipertimbangkan dampak penurunannya jika dermaga ingin mencapai umur layannya. Jenis material reklamasi yang baik untuk suatu bangunan dermaga adalah material pasir atau material batu yang tidak memiliki andil pada penurunan sekunder atau rangkak yang terjadi. Namun, apabila material reklamasi yang digunakan adalah lumpur, sangat diperlukan perhatian dan perhitungan dengan tepat dalam memprediksi kemungkinan penurunan yang terjadi. Penurunan sekunder yang sangat besar dapat terjadi. (Dias, 2003)

Berbeda dengan bangunan perkantoran. Perkembangan arus ekonomi umumnya kemungkinan besar hanya berdampak pada bertambahnya jumlah pekerja dan lapangan pekerjaan. Hal ini tidak menimbulkan peningkatan pembebanan yang signifikan pada bangunan. Maka walaupun bangunan perkantoran ini berdiri diatas 3 jenis material reklamasi yang sudah dibahas sebelumnya, dampak penurunan sekunder yang terjadi sangat kecil.

\section{Material reklamasi yang digunakan}

Material pengisi reklamasi yang digunakan memiliki kelebihan dan kekurangannya masing-masing, seperti yang dibahas pada analisis penurunan sebelumnya.

Untuk material pasir, kelebihannya adalah tidak mengalami penurunan sekunder (secondary settlement), memiliki angka pori yang kecil dan permeabilitas yang tinggi, material tidak terlalu berat sehingga mudah dalam transportasi menuju ke lokasi reklamasi dan tidak berdampak besar dalam settlement yang terjadi. Namun material pasir juga memiliki beberapa kekurangan, yaitu biayanya lebih mahal, ada kemungkinan terjadinya fenomena liquifaksi, sulit dalam pemompaan ke lokasi reklamasi.

Untuk material lumpur, kelebihannya adalah biaya lebih murah dan jumlahnya banyak, mudah dalam pemindahan ke lokasi reklamasi, lebih ringan dibanding material lainnya. Namun material lumpur juga memiliki beberapa kekurangan, diantaranya dapat menimbulkan secondary settlement yang besar, diperlukan perhatian lebih karena tingkat permeabilitasnya yang rendah sehingga perlu waktu yang lebih lama untuk konsolidasi, dan diperlukan vertical drain untuk mempercepat konsolidasi

Untuk material batu, kelebihannya adalah pada umumnya material ini tidak mengalami penurunan sekunder (secondary settlement), kemungkinan terjadinya fenomena liquifaksi sangat kecil, memiliki ukuran yang besar sehingga cocok untuk proyek reklamasi berskala besar. Namun material batu ini juga memiliki kekurangan, yakni cukup berat dibanding material lainnya sehingga dapat berdampak pada penurunan primer yang cukup besar terhadap tanah asli dibawahnya, lebih berat dan sulit dalam pemindahan ke lokasi reklamasi, dan dapat mengalami pelapukan menjadi bentuk yang lebih kecil.

\section{Lingkungan di sekitarnya}

Setiap jenis tanah pengisi reklamasi memiliki tingkat kerusakan yang berbeda-beda. Dampak cuaca seperti kelembaban dan panas dapat memicu terjadinya pelapukan. Dalam hal ini, yang membutuhkan perhatian besar adalah material batu yang dapat melapuk menjadi material yang lebih kecil. Pelapukan batuan ini dapat menyebabkan terjadinya penurunan void ratio pada lapisan tanah pengisi reklamasi.

Pada bangunan dermaga, tentunya lokasi dermaga ini berdekatan dengan perairan (laut). Lokasi dan lingkungan di sekitar dermaga ini tentunya memiliki kelembaban yang sangat tinggi. Tidak menimbulkan masalah yang besar apabila jenis material dibawahnya berupa pasir dan lumpur. Namun, apabila jenis material pengisi reklamasi dibawahnya adalah material batu, maka perlu dipertimbangkan lebih dalam mengenai dampak pelapukan dan penurunan yang akan terjadi di masa depan. (Dias, 2003)

Pada bangunan perkantoran, umumnya bangunan perkantoran berada di tengah kota yang jauh dari perairan. Namun dampak cuaca berupa hujan dan panas tidak dapat dihindarkan. Sama seperti bangunan dermaga, apabila jenis material pengisi reklamasi adalah material batu, perlu pertimbangan matang akan pelapukan yang dapat ditimbulkan dan penurunan yang dapat terjadi.

\section{KESIMPULAN}

Berdasarkan hasil analisis yang dilakukan, dapat didapatkan beberapa kesimpulan sebagai berikut:

1. Berdasarkan analisis penurunan yang terjadi, penurunan sekunder yang terjadi dengan lapisan material pasir (diambil dense sand) sebesar 0.3189 meter dan lapisan material batu ( diambil rock/well graded gravel) sebesar 0.3127 meter. Dari hasil tersebut, penurunan dianggap kecil dan kurang lebih hampir sama sehingga dapat dianggap baik sebagai material pengisi reklamasi.

2. Berdasarkan analisis penurunan pada material lumpur (dredged mud), didapat hasil penurunan sebesar 0.9227 meter. Dari hasil tersebut, terlihat terjadi perbedaan yang signifikan dengan material batu dan pasir. Material lumpur ikut berdampak dalam penurunan sekunder sehingga penurunan yang terjadi lebih besar. 
3. Untuk bangunan dermaga yang diharapkan mencapai umur layan 100 tahun, perlu mempertimbangkan peningkatan pembebanan bertahap dan dampak penurunan yang terjadi akibat perkembangan sosial dan ekonomi. Sedangkan untuk bangunan perkantoran, peningkatan pembebanan tidak terlalu signifikan terjadi akibat perkembangan sosial dan ekonomi.

\section{DAFTAR PUSTAKA}

Arulrajah, Arul. (2008). Case Study of the Changi East Land Reclamation Project, Singapore. $6^{\text {th }}$ Internasional Conference on Case Histories in Geotechnical Engineering, 11-16 Agustus 2008, 1-12.

British Standart. (1992). Guide to Durability of Buildings and Buildings Elements, Products, and Components. Bsi standarts publication, England.

Budhu, M. and J.E. Bowles. (2015). Soil Parameters and Correlation. John Wiley \& Sons, New York.

Das, Braja M. (2002). Mekanika Tanah (Prinsip-Prinsip Rekayasa Geoteknis) Jilid 2. Penerbit Erlangga, Jakarta.

Dias, W.P.S. (2003). Factors Influencing the Service Life of Buildings. The Institution of Engineers, Sri Lanka.

HKDSE Geography. (2014). External Processes and The Landscapes. Hong Kong Geography Authority Publications, Hong Kong.

Kansai International Airport (2016). Why settlement occurs. Tersedia di http://www.kansaiairports.co.jp/en/efforts/our-tech/kix/sink/sink2.html (1 Desember 2018)

Pratikso. (2008). Mekanika Tanah. Fakultas Teknik Unissula, Jakarta 
